\title{
KEBUDAYAAN BATU BESAR DI NIAS SELATAN
}

\section{Oleh : Syamsir Alam \\ Direktorat Permuseuman, Ditjenbud, Depdlkbud.}

\section{PENDAHULUAN.}

Tulisan ini didasarkan atas hasil survei Antropologi Museum ke Nias Selatan pada tahun 1980. Pada waktu itu penulis bersama-sama dengan Drs. Sulaiman Yusuf, Dra. Suwati Kartiwa, Drs. M. Yamin Data, dan Drs. I Made Seraya melakukan survai Antropologi di Nias Selatan selama satu setengah bulan. Survei ini dipimpin dan dibimbing oleh Prof. Dr. A. A. Gerbrands. Kami ditempatkan di lima desa yang ada di Nias Selatan dan Tengah, dengan pembagian daerah survei sebagai berikut:

1. Drs. Sulaiman Yusuf di desa Orahili, Nias Tengah ;

2. Dra. Suwat Kartiwa di desa Botohilitano ;

3. Drs. M. Yamin Data di desa Orahili, Nias Selatan ;

4. Drs. I Made Seraya di desa Bawomatuluo, Nias Selatan; dan

5. Drs. Syamsir Alam di desa Hilinawalo Mazingo, Nias Selatan.

Dilihat dari desa tersebut, satu desa dengan desa lainnya saling berjauhan kecuali desa Orahili dan Bawomatuluo. Dengan letak tempat bertugas yang saling berjauhan, maka sangat sulit bagi petugas survei untuk berkomunikasi satu dengan lainnya. Pembagian yang demikian ini memang disengaja oleh pembimbing karena pembimbing beranggapan bahwa seorang petugas survei harus mampu berdiri sendiri dalam menghadapi masalah yang timbul di lapangan. Namun pada saat yang telah ditentukan semua petugas survei diminta datang ke markas pembimbing. di Teluk Dalam untuk membahas segala sesuatu yang ada hubungannya dengan kegiatan survei. Sebelum berangkat ke Nias, kami diberi pengarahan mengenai tugas dan gambaran tentang alam serta budaya sukubangsa Nias. Selain pengarahan, juga diputarkan film menenai Nias dan diberikan pula bahan bacaan yang ada hubungannya dengan sukubangsa Nias. Kesemuanya ini dimaksudkan agar kami mendapatkan gambaran tentang kehidupan sukubangsa Nias yang akan menjadi obyek penelitian. Sesuai dengan jadwal yang telah ditentukan, maka rombongan survei berangkat dari Jakarta menuju Medan, dengan pesawat udara. Setibanya di lapangan terbang Binaka (Nias), rombongan lalu menuju Gunung Sitoli. Keesokan harinya rombongan menuju Teluk Dalam (Nias Selatan) dengan perahu motor. Perjalanan dari Gunung Sitoli ke Teluk Dalam cukup mendebarkan hati karena satu malam di atas perahu motor dalam gelombang besar lautan Indonesia. Tiba di pelabuhan Teluk Dalam pagi hari. Salah satu ucapan selamat datang dalam bahasa Nias adalah ya'ahowu. kata-kata ini selalu terucap dari penduduk setempat apabila melihat penumpang yang baru turun dari kapal. Pada hari itu juga tiga orang petugas survei langsung diantarkan ke desa yang telah ditentukan, sedangkan penulis dan Drs. Sulaiman Yusuf ter- 
paksa bermalam di Teluk Dalam karena tempat kami bertugas letaknya sangat jauh. Esok paginya barulah kami diantarkan ke desa Hilinawalo Mazingo, sebuah desa pedalaman yang ada di atas gunung.

\section{II.SUKUBANGSA NIAS.}

Penduduk pulau Nias mempunyai kebudayaan yang belum pernah terpengaruh oleh kebudayaan Hindu dan Islam. Sukubangsa ini mengembangkan kebudayaan sendiri yang telah berkembang dan menjadi mantap di pulau ini sejak zaman perunggu dengan kebudayaan batu besar (megalitik), yang telah dibawa dari benua Asia.

Asal usul nenek moyang orang Nias (ONO NIHA) yang orang-orangnya berkulit lebih kuning dari orang Indonesia lainnya, belum dapat diketahui secara pasti. Namun ada seorang ahli Antropologi Belanda yang bernama Prof. Dr. A.A. Gerbrands berpendapat bahwa kemungkinan nenek moyang orang Nias berasal dari Birma. Pendapat ini dikemukakannya atas dasar adanya persamaan tari di Nias dan Birma.

Menurut Gerbrands, tari harimau di dunia ini hanyaada di Nias dan Birma. Atas dasar persamaan inilah pendapat itu dikemukakannya. Sebagai tambahan besar kemungkinan nenek moyang sukubangsa Nias datang ke Nias dari Birma dengan naik perahu. Pada zaman dahulu (abad ke 15) Birma memang terkenal sebagai tempat pembuatan perahu-perahu besar di Asia Tenggara. Di Nias selatan sendiri, rumah adat juga bentuknya seperti perahu, antara lain tercermin pada papan pipih (siloto) yang ada di kiri dan kanan bagian samping rumah tersebut. Sejauh mana pendapat ini dapat dibuktikan, masih diperlukan penelitian lebih lanjut.

Bahasa yang dipengunakan sukubangsa Nias adalah bahasa Nias. Apabila bahasa Nias dibandingkan dengan bahasa Nusantara lainnya, maka ada sedikit perbedaan. Walaupun bahasa Nias termasuk rumpun bahasa Melayu Polinesia, keistimewaan yang ada dalam bahasa Nias antara lain sifat bahasanya yang vokalis, tidak mengenal huruf mati di tengah atau di belakang sukukata. Sukubangsa Nias tidak mempunyai huruf sendiri. Huruf yang dipergunakan oleh sukubangsa Nias adalah huruf latin yang penulisannya terpengaruh oleh bahasa Jerman. Hal ini dapat dimaklumi karena bangsa Jerman adalah bangsa yang pertama kali mempengaruhi $\mathrm{Ke}$ budayaan mereka melalui penyebaran agama. Penulisan huruf vokal $\mathrm{O}$ yang diberi titik dua buah diatasnya (ö) dibaca e (dibaca e pepet), bukan dibaca e yang digunakan tanda aksen di atasnya (é). Bahasa Nias mempunyai dua logat bahasa yaitu logat Nias Utara dan logat Nias Selatan atau Tello. Logat Nias Utara dipengunakan di Nias bagian Utara, Timur dan Barat, sedangkan logat Nias Selatan dipengunakan di Nias Selatan, Nias Tengah dan Kepulauan Batu.

Selanjutnya mengenai jumlah penduduk pulau Nias, pada tahun 1914 tercatat 135.000 jiwa, sedangkan angka terakhir yang kami peroleh dari Kantor Departemen Pendidikan dan Kebudayaan kabupaten Nias pada tahun 1980 tercatat 431.852 jiwa. 
Pulau Nias adalah sebuah pulau yang dikelilingi oleh lautan Indonesia. Gelombang lautan ini sangat besar terutama di sebelah barat pulau ini. Pedalaman pulau ini tertutup oleh hutan sekunder. pada bagian tengah agak ke selatan dari pulau ini terdapat gunung-gunung, antara lain gunung Halilolomatua dengan tinggi 886 meter. Adapun sungai-sungai yang ada di pulau ini airnya sangat dangkal sehingga tidak memungkinkan untuk dilayari. Satu-satunya sarana perhubungan di pulau ini adalah jalan darat. Keadaan jalan-jalan dan jembatan di pulau Nias yang merupakan peninggalan kolonial Belanda, baru sebagian kecil yang diperbaiki. Keadaan ini mengakibatkan komunikasi antara desa yang satu dengan desa lainnya agak terhambat. Khususnya di Kecamatan Teluk Dalam memang ada beberapa ruas jalan yang menghubungkan Teluk Dalam dengan Bawomatullo. Teluk Dalam dengan Hilisimaitono, dan Teluk Dalam dengan Botohilitano. DAri Teluk Dalam ke desa-desa lainnya masih dihubungkan dengan jalan setapak. Desa-desa (banua-banua) di Nias yang letaknya di Pedalaman sangat sulit didatangi karena desa-desa tersebut berada di puncak-puncak bukit atau gunung. Oleh karena itu kebanyakan desa-desa di Nias memakai nama bukit (bawo) dan gunung (hili). Desa-desa tersebut terletak di atas bukit atau di atas gunung. Menurut sejarah antara desa-desa di Nias pada zaman dahulu sering terjadi peperangan. Guna mempertahankan serangan dan untuk dapat mengintai musuh, maka dibangunlah desa-desa di atas bukit atau gunung. Apabila desa tersebut mendapat serangan dari desa lain, sekeliling desa itu dibuat parit dan ditanami pohon bambu, untuk pertahanan. Bentuk desa Nias, terutama di bagian tengah dan Selatan berbentuk U dengan rumah kepala desa (salawa) atau kenala negeri (tuhenori) terletak di tengah bagian ujung sebagian pusat desa, menghadap lapangan! desa yang dilandasi dengan batu-batu pipih. Dua sisi dari lapangan itu merupakan rumah penduduk. Rumah penduduk ini satu sama lainnya saling berhubungan. Ada pintu khusus yang menghubungkan rumah-rumah tersebut. Pada zaman dahulu fungsi pintu-pintu itu adalah untuk memudahkan dalam bergerak apabila ada lawan di halaman desa. Adapun bentuk desa di Nias Utara, Timur dan Barat tidak seperti huruf $U$ melainkan dua garis sejajar.

Bentuk rumah adat di Nias ada dua macam. Di Nias bagian Selatan dan Tengah berbentuk empat persegi panjang dan bertiang, sedangkan di Nias bagian Utara, Timur dan Barat bentuknya bulat telur (oval) dan bertiang. Ruangan yang ada di dalam rumah adat dapat dibagi dua yaitu ruangan sebelah depan untuk menerima tamu, sedangkan ruangan di bagian belakang untuk para keluarga pemilik rumah. Bagi orang asing (tamu) yang belum dianggap keluarga dilarang keras untuk masuk ke ruangan bagian belakang.

Di muka rumah tradisionil ini pada umumnya terdapat bangunan-bangunan megalithik seperti tugu batu (menhir), yang disebut saita gari (Nias Selatan), behu (Nias Tenggara), dan gowezalava (Nias Utara, Timur dan Barat). Selain itu di depan rumah terdapat tempat duduk dari batu-batu besar (daro-daro) atau harefa. Bangunan tersebut pado zaman dahulu dibuat untuk membuktikan bahwa si pemilik ru- 
mah pemah mengadakan acara adat, sehingga dapat dianggap sebagai lambang dalam rangka menaikkan status sosial dalam masyarakat. Acara semacam itu cukup mahal karena harus menjamu orang banyak dan memotong piaraan babi. Makin banyak babi yang dipotong, makin tinggi martabat orang tersebut. Pada waktu kami berada di Nias Selatan, hal semacam itu pernah kami tanyakan kepada penduduk setempat, yang dijawab bahwa hanya orang kaya saja yang dapat melakukan hal seperti itu. Walaupun demikian, hal semacam itu masih ada di Nias Selatan. Sela in itu masih ada bangunan batu untuk latihan loncat tinggi (zawo-zawo). Pada zaman dahulu ilmu loncat tinggi sangat penting bagi penduduk laki-laki dalam rangka menyerang lawan. Menurut keterangan penduduk setempat, pada zaman dahulu seorang pemuda Nias yang tidak dapat loncat tinggi, maka dia tidak diperkenankan untuk ikut berperang.

Religi atau kepercayaan asli penduduk pulau Nias adalah Pelebegu. Pelebegu merupakan nama yang diberikan oleh pendatang yang artinya "penyembah roh". Nama yang diberikan oleh penganutnya sendiri adalah molohe adu (penyembah adu). Sifat kepercayaan asli ini menyembah pada roh leluhur yang mereka manifestasikan dalam patung-patung kayu yang disebut adu. Patung kayu yang ditempati oleh roh leluhur tersebut patung Adu Satua. Kemudian dengan datangnya bangsa Barat pada abad ke 19 khususnya bangsa Jerman dan Belanda yang menyiarkan agama, maka patung-patung setempat tidak menyembah patung (Adu) lagi, setelah itu proses kristenisasi dimulai di pulau Nias. Selain itu di pulau Nias terdapat pula agama Islam yang dianut orang Nias keturunan Minangkabau, Aceh dan Bugis. Sedangkan agama Buddha dianut oleh orang Nias keturunan Cina.

\section{RUMAH RAJA ADAT (OMA SABUA) DI NIAS SELATAN.}

Salah satu unsur kebudayaan Nias yang sangat menonjol adalah rumah raja adat. Rumah ini lebih besar dari rumah penduduk lainnya. Dalam satu desa hanya ada satu rumah raja adat. Sekarang ini banyak desa-desa di Nias Selatan tidak mempunyai lagi rumah raja adat. Ada yang punah karena dimakan usia, dan ada pula yang musnah karena terbakar. Rumah raja adat ini adalah rumah bertiang yang dibuat dari kayu-kayu pilihan. Adapun kayu yang dipilih untuk bangunan tersebut antara lain : kayu manwadani, kayu afos, kayu siholi, kayu manawabanua, dan kayu tuhugeu. Sekarang ini kayu-kayu tersebut sudah sulit didapat karena hutan-hutan primer sudah banyak yang dibabat untuk perladangan. Sebagai gantinya sudah banyak penduduk yang membangun rumahnya dengan beton seperti rumah dikota. Menurut catatan dan pengamatan kami, di Nias Selatan sekarang tingga empat buah rumah raja adat yaitu di desa Bawomatullo, desa Hilinawalo Fau, desa One Hondre, dan desa Hilinawalo Mazingo. Di depan rumah raja adat tersebut terdapat batu- 
batu besar sepert daro-daro. Didepan rumah raja adat Bawomatullo terdapat daro-daro, tugu yang menyerupai phallus, dan zawo-zawo. Di depan rumah raja adat Hilinawalo Fau terdapat daro-daro, tugu batu (menhir) dan batu yang bentuknya seperti peti untuk tempat barang. Di depan rumah raja adat One Hondre terdapat daro-daro. Demikian pula di depan rumah raja adat di desa Hilinawalo Mazingo terdapat daro-daro yang bentuknya sangat sederhana dan belum diupam. Selain desa tersebut di atas, kami juga mengunjungi desa Hilisimaitono. Di desa ini sudah tidak ada lagi rumah raja adat. Akan tetapi di desa ini ada peninggalan batu-batu besar berupa kursi batu, dan meja batu. Sangat disayangkan kursi batu itu telah rusak. Walaupun demikian sisa-sisanya masih ada yaitu di belakang rumah ama Elvis (bapak Elvis), sehingga apabila akan dilakukan rekonstruksi sisa-sisanya itu dapat disatukan dengan yang terletak di halaman desa.

\section{PENUTUP.}

Tradisi kebudayaan batu-batu besar atau Megalithik di Nias Selatan sampai saat ini masih tetap bertahan walaupun sudah ada pengaruh kebudayaan asing yang masuk ke Nias. Khususnya di desa Bawomatuluo, daro-daro, zawo-zawo dan lainnya tetap terpelihara dengan baik karena desa tersebut oleh pemerintah dikembangkan sebagai daerah pariwisata. 


\section{KEPUSTAKAAN}

Callenfels, Van Stein. 1974. Pedoman Singkat Koleksi Prasejarah Museum Pusat Lembaga Kebudayaan Indonesia. Jakarta: Proyek Rehabilitasi dan Perluasan Museum DKI Jakarta.

Danandjaya, J. 1976. "Penduduk kepulauan sebelah Barat Surnatera". Dalam Koentjaraningrat editor Manusia dan Kebudayaan di Indonesia. Jakarta: Jambatan.

Felman, Jerome Allen. 1977. The Architecture of Nias, Indonesia With Special Reference to bawomatuluo Village (disertasi) Columbia University.

Quartantyo, Djoko. 1979. Teluk Dalam dengan desa-desa di Bukit. Jakarta: Surat Kabar Suara Karya. 


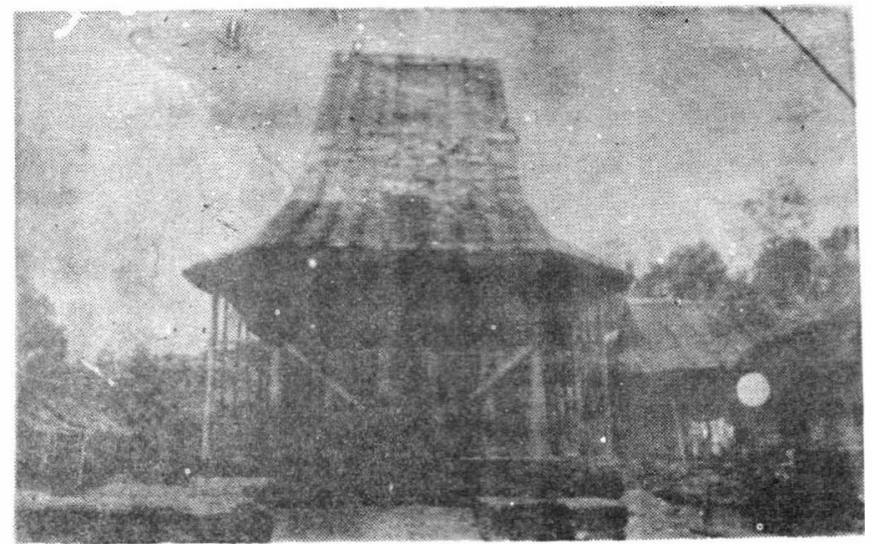

Rumah Raya Adat Nias Selatan di Desa Hilinawalo Mazingo.

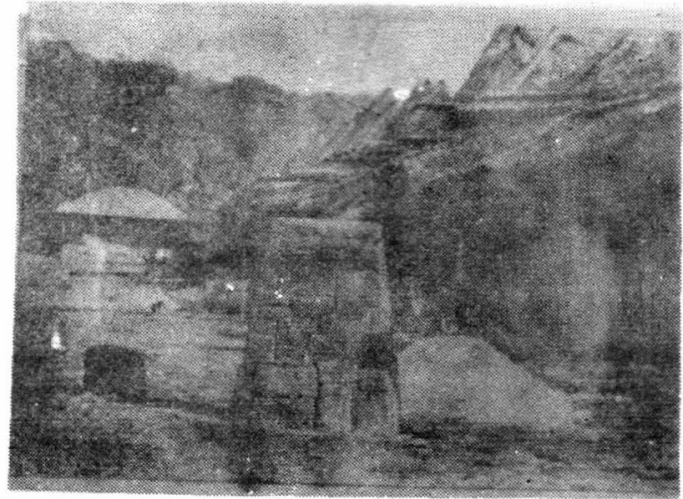

Batu untuk Lompat Tinggi di desa Hilisimaitano. 


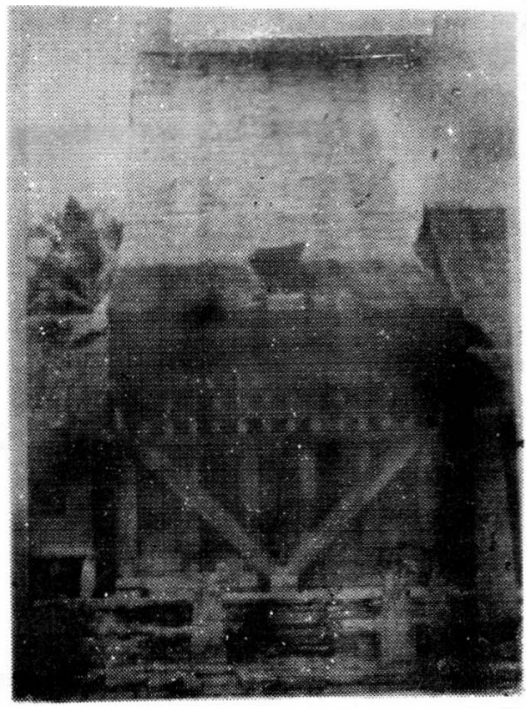

Rumah Raja Adat di desa Hilinawalo Fau.

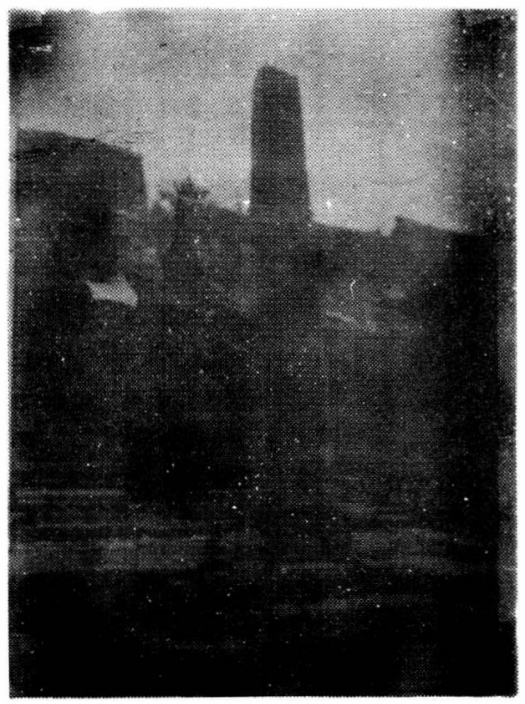

Tugu batu di depan rumah raja adat di desa Hilinawalo Fau. 